\title{
Perancangan perbaikan equipment kalibrasi pressure gauge dengan metode analisis perancangan kerja di PT. Surya Toto Indonesia Tbk
}

\author{
Junaedi ${ }^{1}$, Wanto Sarwoko ${ }^{2}$, Riki Effendi ${ }^{*}$ \\ 1,2Jurusan Teknik Industri, Universitas Pamulang, Tangerang Selatan \\ Jl. Surya Kencana No. 1 Pamulang, Indonesia 15417 \\ ${ }^{2}$ Program Studi Teknik Mesin, Fakultas Teknik, Universitas Muhammadiyah Jakarta, \\ JI. Cempaka Putih Tengah 27 Jakarta Pusat, Indonesia 15417 \\ ${ }^{\star}$ Corresponding author: riki.effendi@ftumj.ac.id
}

\begin{abstract}
In the calibration process of pressure gauge is very much needed accuracy, which can time consuming, especially in the inspection process and will affect the correction value of each inspection process. The work design application method is very useful for learning the principles and mechanisms for obtaining a better work system design or method. With using work design analysis then the work process is mapped into work maps. The aim of the research is to minimize working time by using work design application methods to determine the standard time and improvements that must be made by company. The results showed that the standard time for the pressure gauge calibration process before improvement was 3248.44 seconds. By using work design analysis, the time of the pressure gauge calibration process becomes more efficient with a standard time of 2291.86 seconds with an efficiency value of $91.72 \%$.
\end{abstract}

Keywords: Design, pressure gauge calibration equipment, work design method.

\begin{abstract}
Abstrak
Dalam proses kalibrasi alat ukur tekanan (pressure gauge) sangat dibutuhkan keakuratan yang dapat memakan waktu, terutama pada proses pemeriksaan dan akan berpengaruh pada nilai koreksi dari setiap proses pemeriksaan. Metode aplikasi desain kerja sangat berguna untuk mempelajari prinsip-prinsip dan mekanisme untuk mendapatkan desain atau metode sistem kerja yang lebih baik. Dengan menggunakan analisis perancangan kerja maka proses kerja tersebut dipetakan ke dalam peta kerja. Tujuan dari penelitian ini adalah meminimalkan waktu kerja dengan menggunakan metode aplikasi desain kerja untuk menentukan standar waktu dan perbaikan yang harus dilakukan oleh perusahaan. Hasil penelitian menunjukkan bahwa waktu standar untuk proses kalibrasi alat ukur tekanan sebelum perbaikan adalah 3248,44 detik. Dengan menggunakan analisis desain kerja, waktu proses kalibrasi alat ukur tekanan menjadi lebih efisien dengan waktu standar 2291,86 detik dengan nilai efisiensi $91,72 \%$.
\end{abstract}

Kata Kunci: Perancangan, equipment kalibrasi pressure gauge, metode perancangan kerja.

\section{Pendahuluan}

Pada era pasar bebas saat ini jaminan kualitas produk mutlak menjadi persyaratan yang harus dipenuhi oleh setiap dunia usaha, bidang industri, pendididkan, kesehatan, jasa, dan lain sebagainya. Sejalan dengan itu menjadi sangat perlu sebuah perusahaan untuk mengambil sertifikat ISO (International Standard
Organization) agar produk bisa bersaing di pasar [1]. Agar bisa mendapatkan sertifikat tersebut, salah satu klausul atau persyaratan yang harus dipenuhi sebagai jaminan kualitas serta mendapatkan sertifikat ISO adalah pengendalian alat ukur atau parameter ukur yang digunakan untuk pengukuran setiap proses yang memerlukan proses pengukuran. Bentuk 
pengendaliannya dengan melakukan kalibrasi setiap alat ukur atau parameter ukur yang dipergunakan untuk proses pengukuran sebagai jaminan kualitas produk yang dihasilkan.

Untuk memberikan jaminan tersebut, perusahaan yang sudah mendapat sertifikat ISO diwajibkan melakukan kalibrasi terhadap alat ukur atau parameter ukur yang dipergunakan untuk proses pengukuran. Seiring dengan itu untuk memberikan jaminan akan kualitas alat ukur pada saat ini laboratorium kalibrasi menjadi solusi yang tepat, sehingga pada saat ini banyak berdiri laboratoriumlaboratorium kalibrasi di lingkungan perusahaan atau laboratorium kalibrasi yang khusus memberikan layanan kalibrasi baik swasta atau intansi pemerintah seperti KIM LIPI, DIMET, yang proses kalibrasinya mengacu pada ISO/IEC 17025:25 [2][7].

PT. Surya Toto Indonesia Tbk mempuyai total alat ukur 8525 pcs, dimana 7882 pcs kalibrasi internal dan 643 pcs kalibrasi external. Dengan aplikasi perancangan kerja saat ini seorang petugas kalibrasi hanya sanggup melakukan kalibrasi alat ukur sebanyak 7 pcs sampai dengan 8 pcs perhari. Sementara jumlah alat ukur yang harus dikalibrasi setiap tahunnya terus meningkat.

Karena proses kalibrasi masih ada yang menggunakan proses kalibrasi manual, seperti kalibrasi alat ukur pressure gauge, yang dikalibrasi mengunakan "Hydraulic power equipment", dimana hydraulic power equipment ini cara pengoperasiannya dengan sistem pompa dan pressure gauge harus dikalibrasi minimal 3 titik dan maksimal 5 titik dan setiap nilai penunjukan diuji 3 kali pengukuran, untuk mendapatkan pengukuran yang lebih akurat tetapi memakan waktu yang cukup lama. Untuk itu metode perancangan perbaikan kerja sangat dibutuhkan karena berarti perusahaan akan dapat meminimasi waktu kerja.

\section{Tinjauan Pustaka}

Kalibrasi adalah serangkaian kegiatan untuk menentukan kebenaran konvensional petunjukan instrument ukur dan bahan ukur dengan cara membandingkan terhadap harga yang diabadikan/standar yang telusur ke standar nasional maupun internasional. Analisa Perancangan Kerja adalah suatu ilmu yang mempelajari prinsip dan mekanisme untuk memperoleh suatu rancangan atau metode sistem kerja yang lebih baik [2][3][10]. Dalam hal ini metode kerja yang dihasilkan haruslah metode yang efektif dan efisien. Dilihat dari sejarahnya, disiplin Ilmu Teknik Industri dimulai dari perbaikan sebuah sistem kerja yang dianggap sebagai sebuah teknik manajemen maka dapat dikatakan bahwa Teknik Tata Cara Kerja sebagai disiplin ilmu TI yang pertama Cara Westinghouse mengarahkan penilaian pada 4 faktor yang dianggap menentukan kewajaran dan ketidakwajaran dalam bekerja yaitu keterampilan, usaha, kondisi kerja, dan konsistensi. Setiap faktor terbagi dalam kelas-kelas dengan nilai masingmasing. Westinghouse sistem of rating [4] [8], cara ini didasarkan atas penelitian terhadap empat faktor.

\section{Metode Penelitian}

Pengolahan data pada penelitian ini berupa analisa proses kalibrasi alat ukur pressure gauge dengan metode Westinghouse [4][5][9]. Untuk mengetahui dan menentukan waktu baku dari proses kalibrasi sekarang merupakan tahapan mengenai kerangka penelitian proses kalibrasi alat ukur pressure gauge yang diamati.

Pembuatan peta-peta kerja pada bagian ini akan dilakukan pengamatan untuk mengetahui perhitungan waktu proses kalibrasi alat ukur pressure gauge. Peta-peta yang digunakan di dalam pengukuran waktu proses kalibrasi alat ukur pressure gauge.

1. Peta Aliran Proses

2. Diagram Alir 
3. Peta Tangan Kiri dan Kanan

Analisa waktu kalibrasi alat ukur pressure gauge. Pada tahap ini akan dilakukan analisa terhadap waktu proses kalibrasi sekarang dengan menggunakan Metode Westinghouse dan metode-metode yang digunakan.

1. Perhitungan Waktu Siklus

2. Perhitungan Waktu Normal

3. Perhitungan Waktu Baku

4. Rancangan Design hydraulik power equipment.

Pada tahap ini akan dilakukan analisis rancangan hydraulic power equipment yang dirancang menjadi Paralel combination.

Peta-peta yang digunakan di dalam pengukuran waktu proses kalibrasi alat ukur pressure gauge sesudah perancangan.

1. Peta Aliran Proses

2. Diagram Alir

3. Peta Tangan Kiri dan Kanan

Analisis terhadap waktu proses perancangan kalibrasi alat ukur pressure gauge yang dikombinasikan dengan menggunakan Metode Westinghouse dan metode-metode yang digunakan [6].

1. Perhitungan Waktu Siklus.

2. Perhitungan Waktu Normal.

3. Perhitungan Waktu Baku.

Melakukan hasil perbandingan waktu proses kalibrasi alat ukur pressure gauge sebelum perancangan, dengan waktu proses kalibrasi pressure gauge sesudah perancangan. Selanjutnya menganalisis perhitungan waktu efisiensi proses kalibrasi alat ukur pressure gauge sebelum perancangan dan sesudah peracangan.

\section{Hasil dan Pembahasan}

\section{Perkembangan jumlah alat ukur pressure gauge}

Perkembangan jumlah alat ukur pressure gauge di PT. Surya Toto Indonesia setiap tahunnya semakin bertambah, terlihat dari tahun 2015 sampai dengan tahun 2019. Data tersebut dijabarkan melalui Tabel 1.
Tabel 1. Perkembangan jumlah alat ukur

\begin{tabular}{ccc}
\multicolumn{3}{c}{ pressure gauge } \\
\hline NO & TAHUN & JUMLAH \\
\hline 1 & 2015 & 411 \\
2 & 2016 & 432 \\
3 & 2017 & 584 \\
4 & 2018 & 600 \\
5 & 2019 & 672 \\
\hline
\end{tabular}

PT. Surya Toto Indonesia, mempunyai kegiatan non produksi salah satunya bagian departemen kalibrasi yang bertugas mengendalikan alat ukur yang bertujuan untuk menjamin alat ukur agar sesuai dengan spesifikasinya. Alat ukur yang waktu pemeriksaanya paling lama adalah alat ukur tekanan atau pressure gauge, karena dalam proses pemeriksaan masih dengan mengunakan proses manual. Dengan cara mengkalibrasi pressure gauge menggunakan hydraulic power equipment. Dengan cara pemeriksaan satu alat ukur satu proses. Setiap kali melakukan pemeriksaan pressure gauge yang harus dikalibrasi 3 titik pengukuran naik dan tiga titik pengukuran turun, semakin banyak pengukuran tingkat nilai pengukuran yang didapat semakin akurat, karena proses pemeriksaan masih manual untuk melakukan pengukuran untuk mencapai pengukuran yang akurat, memerlukan waktu yang cukup lama. Untuk memaksimalkan penelitian dan peningkatkan waktu kerja yang efisien, maka perlu diawasi, dikontrol, dan melakukan perbaikan proses pemeriksaan pressure gauge kalibrasi dengan menggunakan hydraulik power equipment.

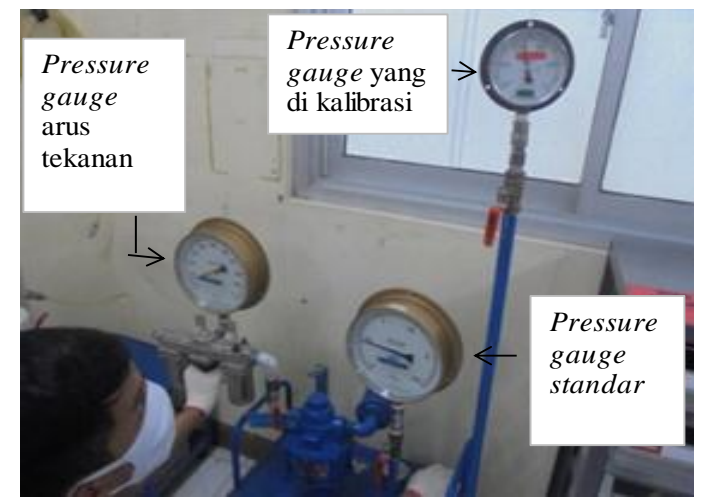

Gambar 1. Proses kalibrasi power hydraulic equipment 
2. Proses kalibrasi pressure gauge hydraulic power equipment

Langkah-langkah proses kalibrasi pressure gauge dengan mengunakan hydraulik power equipment antara lain:

1. Menerima alat ukur pressure gauge dari seksi terkait.

2. Memeriksa kondisi pressure gauge secara visual.

3. Membersihkan alat ukur pressure gauge dan alat kalibratornya.

4. Mengkondisikan alat ukur.

5. Menyiapkan alat kalibrasi yang diperlukan seperti, kain lap, pressure gauge, pressure gauge standar, kunci pass, obeng, dan laporan kalibrasi (Gambar 2).

6. Memasang pressure gauge untuk tekanan pengukur tekanan sumber angin masuk.

7. Memasang pressure gauge standar.

8. Memasang pressure gauge yang akan dikalibrasi.

9. Membuka stop valve pada sumber tekanan. Pada saat memasang pressure gauge tekanan angin masuk, pressure gauge dan pressure gauge standar, memastikan pemasangan kuat, tidak kendor dan memastikan sumber tekanan pada stop valve sudah terbuka (Gambar 3).

10. Membuka regulator.

11. Membuka stop valve pada pressure gauge standar atau kalibrator.

12. Membuka stop valve pada pressure gauge yang akan dikalibrasi.

13. Memutar regulator hingga jarum naik dan berfungsi.

14. Melakukan pemeriksaan pengukuran naik, setiap pengukuran diukur tiga titik, dan melakukan tiga kali pengukuran secara berulang.

15. Mengendorkan regulator hingga jarum turun dan diambil tiga titik pengukuran, dilakukan sampai tiga kali pengukuran secara berulang.

16. Memutar regulator sampai posisi Off dan memastikan stop valve kondisinya Off.

17. Membuat laporan kalibrasi.
18. Menyimpan pressure gauge yang sudah dikalibrasi di tempat pengondisian (Gambar 4 dan 5).

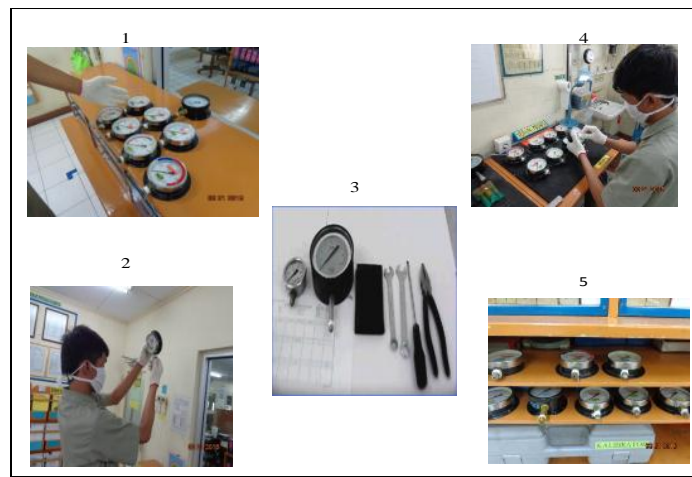

Gambar 2. Perlengkapan dan persiapan proses kalibrasi

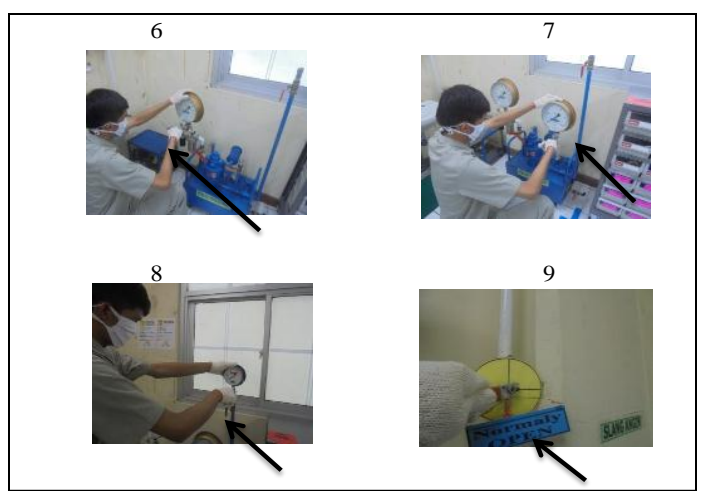

Gambar 3. Pemasangan alat kalibrator dan pressure gauge

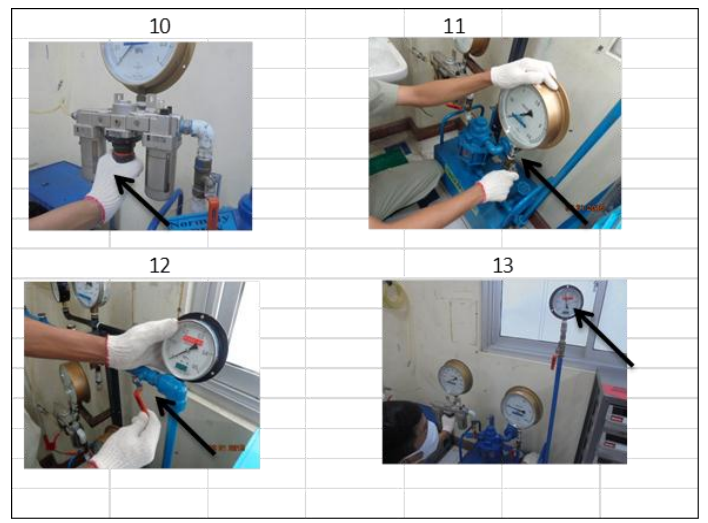

Gambar 4. Penyetingan fungsi tekanan

\section{Peta aliran proses kalibrasi pressure gauge}

Setelah mempunyai gambaran tentang keadaan proses yang terjadi. Seperti diperlihatkan dilakukan proses kalibrasi pressure gauge dengan menggunakan Hydraulic power equipment (Gambar 5). 


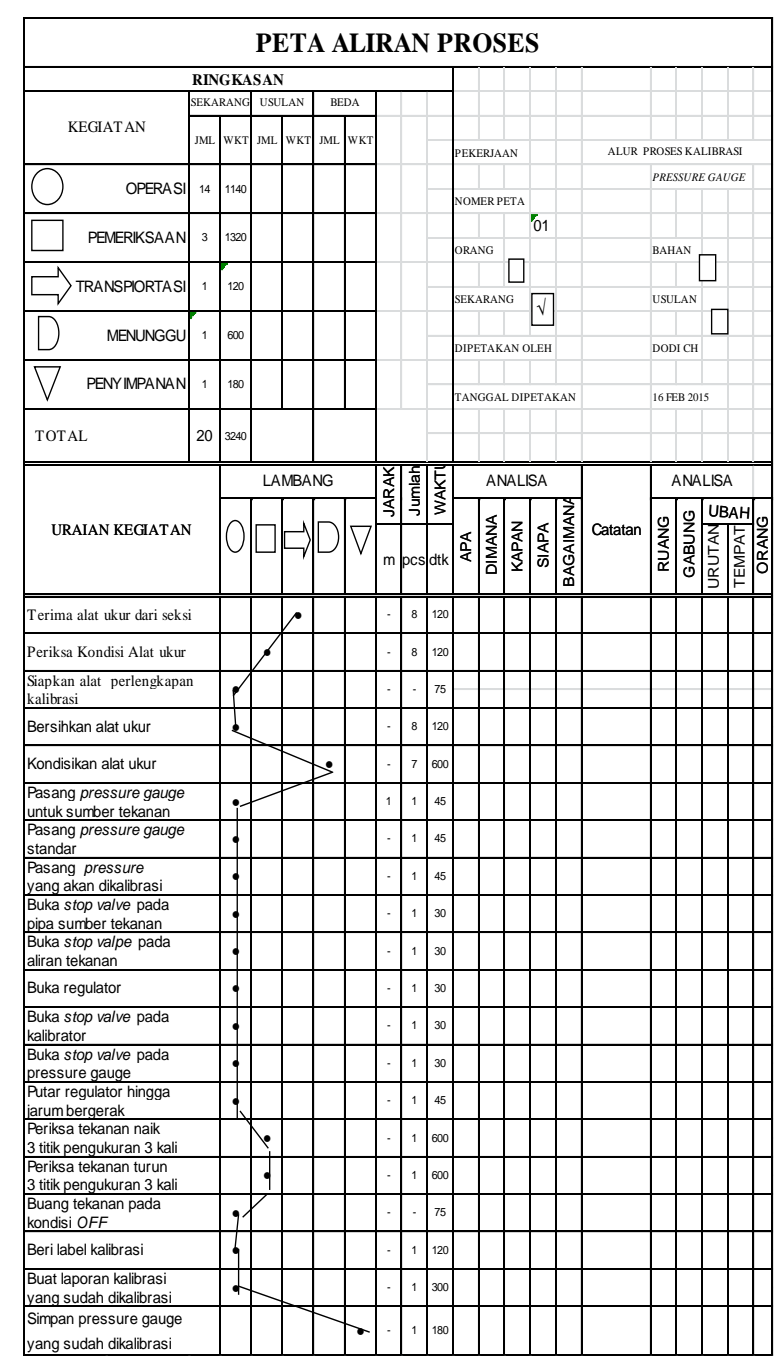

Gambar 5. Peta aliran proses kalibrasi pressure gauge

Berdasarkan peta aliran proses kalibrasi pressure gauge gambar 5 didapat waktu siklus adalah 3.240 Detik.

\section{Menghitung waktu normal berdasarkan metode Westinghouse}

Menghitung waktu normal berdasarkan Westinghouse dengan rumus sebagai berikut:

$$
\mathrm{Wn}=\mathrm{Ws} . \mathrm{P}
$$

Keterangan:

Wn: Waktu Normal.

Ws : Waktu Siklus.

P : Faktor Penyesuaian.

Rating faktor atau penyesuaian pekerjaan dari proses kalibrasi alat ukur pressure gauge, kegiatan ditentukan dengan Metode Westinghouse. Metode Kegiatan proses kalibrasi alat ukur pressure gauge rinciannya
1. Keterampilan: Exellent $(\mathrm{B} 2)=+0,08$

Dengan pertimbangan bahwa operator:

a. Menggunakan Peralatan dengan baik.

b. Gerakan kerjanya dan urutanurutannya dijalankan tanpa kesalahan

c. Percaya pada diri sendiri.

d. Terlihat telah terlatih baik.

e. Tampak cocok dengan pekerjaannya.

2. Usaha: Exellent $(\mathrm{B} 2)=+0,08$

Dengan pertimbangan bahwa operator:

a. Gerakan-gerakan yang salah terjadi sangat jarang sekali.

b. Gerakan-gerakannya lebih ekonomis dari operator biasa.

c. Banyak memberi saran.

3. Kondisi: Exellent $(\mathrm{B})=+0,004$

Dengan pertimbangan bahwa lingkungan tempat kerja:

a. Keadaan pencahayaan baik.

b. Temperatur dan kebisingan juga baik.

4. Konsistensi: Exellent $(\mathrm{C})=+0,03$

Dengan pertimbangan bahwa operator:

a. Waktu penyelesaian pekerjaan tidak berubah.

b. Setiap Elemen pekerjaan diselesaikan dengan baik.

5. Waktu normal proses kalibrasi pressure gauge

Perhitungan $\mathrm{P}$ dengan Metode Westinghouse adalah sebagai berikut:

a. Keterampilan Excellent $(\mathrm{B} 2)=0.08$

b. Usaha Excellent (B2) $\quad=0,08$

c. Kondisi Kerja Exellent $(\mathrm{B}=0,04$

d. Konsistensi Exellent (B) $\frac{=0,03}{=0,23}+$

Jadi $\mathrm{P}=(1-0,23)=0,77$

Sehingga Waktu Normal

$\mathrm{Wn}=\mathrm{Ws} \times \mathrm{P}$

$\mathrm{Wn}=3.240 \times 0,77=2498.8$ Detik

Jadi waktu normal sebesar 2.498,8

Detik

\section{Menghitung waktu baku berdasarkan metode Westinghouse}

Menghitung waktu baku berdasarkan Metode Westinghouse dengan rumus sebagai berikut: 
Keterangan:

$$
\mathrm{Wb}=\mathrm{Wn}(1+\mathrm{l})
$$

Wb: Waktu Baku.

Wn: Waktu Normal.

$l$ : Kelonggaran

Menghitung Kelonggaran:

1. Tenaga yang dikeluarkan : 6

2. Sikap Kerja : 1

3. Gerakan Kerja : 0

4. Kelelahan Mata : 6

5. Keadaan Temperatur Kerja : 0

6. Keadaan Atmos : 10

7. Keadaan Lingkungan $\frac{: 2}{: 25}+$

Jadi Kelonggaran yang didapat pekerja untuk menyelesaikan pekerjanya adalah $25 \%$. Jika dari sampling pekerjaan didapat bahwa kelonggaran untuk terhindarkan adalah 5\%, maka kelonggaran yang harus diberikan untuk pekerja proses kalibrasi alat ukur pressure gauge adalah $(25+5) \%=30 \%$.

Selain menilai rating faktor operator juga ditentukan oleh allowance/kelongaran dari masing-masing kegiatan, pada proses kalibrasi alat ukur pressure gauge pekerja yang melakukannya berjenis kelamin lakilaki, allowance/kelonggaran untuk proses kalibrasi pressure gauge kegiatan pada waktu saat proses kalibrasi dapat dilihat di bawah ini.

Untuk kegiatan Proses kalibrasi pressure gauge:

1. Tenaga yang Dikeluarkan: sangat ringan (beban peralatan dibawah $1 \mathrm{~kg}$ )

2. Sikap kerja: Berdiri diatas dua kaki (badan tegak ditumpu dua kaki)

3. Gerakan kerja: Normal (tangan bekerja secara bebas).

4. Kelelahan mata: Pandangan yang hampir terus menerus, melakukan pekerjaan yang teliti saat proses pemeriksaan.

5. Keadaan temperatur kerja: Normal $20 \pm$ 1 derajat celsius

6. Keadaan atmosfer: Buruk (adanya baubauan berbahaya yang mengakibatkan memakai alat pelindung diri).
7. Keadaan lingkungan baik: jika faktor berpengaruh dapat menurunkan kualitas.

Jika waktu normalnya 2498.8 detik, maka waktu bakunya adalah

$$
\begin{aligned}
\mathrm{Wb} & =\mathrm{Wn}(1+1) \\
& =2498.8+0.3(2498.8) \\
& =2498,8+749.64 \\
& =3248,44 \text { detik }
\end{aligned}
$$

Jadi waktu bakunya adalah 3248,44 detik.

\section{Desain perancangan kerja prosses kalibrasi pressure gauge}

Dari proses kalibrasi sebelumnya pemeriksaan pressure gauge dengan mengunakan hydraulic power equipment dengan cara satu alat ukur satu proses pemeriksaan. Dimana sumber arus tekanan alirannya langsung ke hydraulic power equipment yang memfungsikan pressure gauge yang akan dikalibrasi dan alat standar. Yang menggunakan banyak waktu kerja adalah pada saat waktu pengondisian dan waktu pemeriksaan. Dengan masalah tersebut kemudian dilakukan improvment, dengan merancang suatu perancangan proses kalibrasi pressure gauge dengan hydraulic power equipment. Perancangan dibuat kombinasi dengan penambahan pipa-pipa untuk menempatkan pressure gauge yang lain. Pipa yang dipakai adalah pipa besi yang mampu menahan sumber tekanan (Gambar 6).

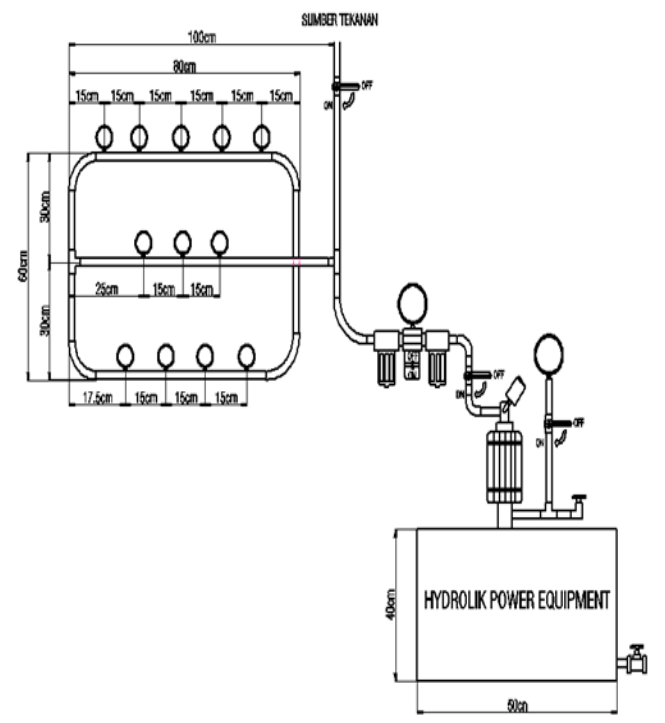

Gambar 6. Perancangan Hydraulic Power Equipment 


\section{Peta aliran proses kalibrasi pressure gauge usulan}

Dari peta aliran proses usulan proses kalibrasi pressure gauge tidak ada waktu pengondisian yang membuat kemacetan dalam proses kalibrasi pressure gauge karena pressure gauge diperiksa sekaligus tidak diperiksa satu pengukuran satu pressure gauge (Gambar 7).

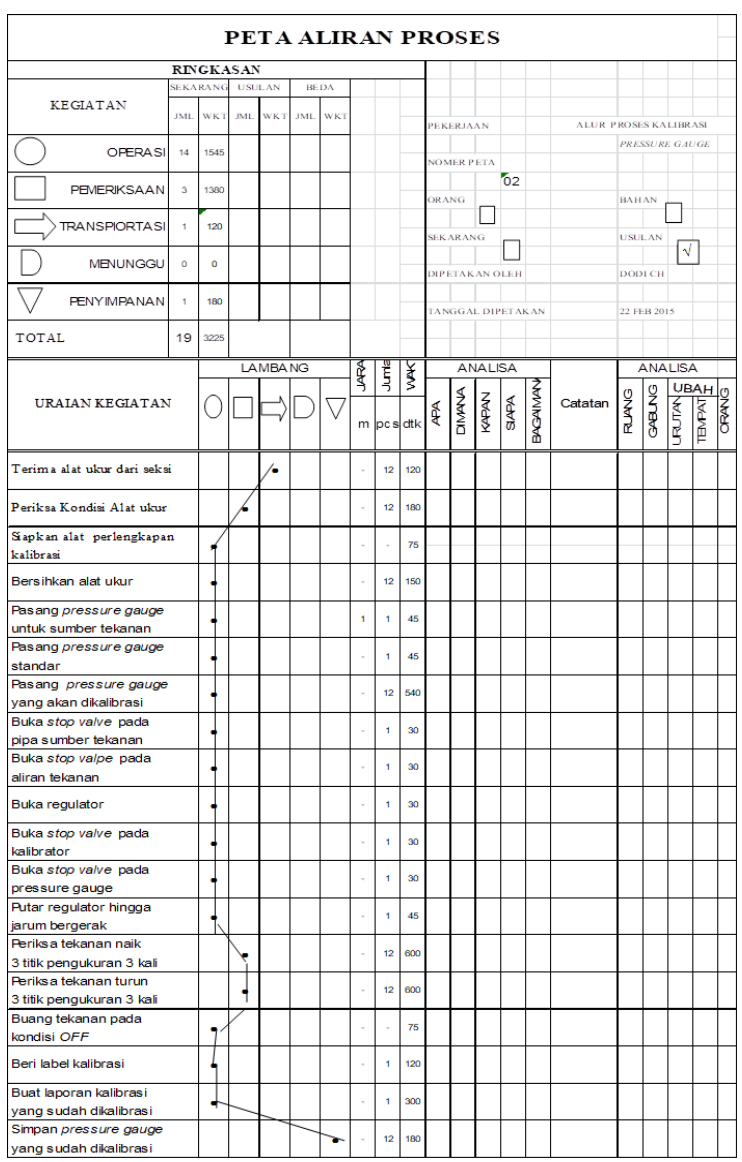

Gambar 7. Peta aliran proses kalibrasi pressure gauge usulan

\section{Waktu siklus proses kalibrasi pressure gauge perbaikan}

Berdasarkan peta aliran proses kalibrasi pressure gauge dengan hydralic power equipment yang dikombinasikan pada gambar 7 didapat waktu siklus adalah 3.225 detik.

\section{Menghitung waktu normal berdasarkan metode Westinghouse Menghitung Waktu Normal} perancangan hydraulic power equipment berdasarkan Metode Westinghouse sebagai berikut:

$$
\mathrm{Wn}=\mathrm{Ws} . \mathrm{P}
$$

Keterangan:

Wn : Waktu Normal.

Ws : Waktu Siklus.

$\mathrm{P}$ : Faktor Penyesuaian.

Waktu normal proses kalibrasi pressure gauge yang dikombinasikan berdasarkan pertimbangan operator sebagai berikut:

1. Keterampilan Excellent (B2) $\quad=0.08$

2. Usaha Excellent

(B2) $\quad=0,08$

3. Kondisi Kerja Exellent (B)

(B) $\quad=0,04$

4. Konsistensi Exellent

$$
\frac{=0,03}{=0,23}+
$$

Jadi $\mathrm{P}=(1-0,23)=0,77$

Sehingga Waktu Normal

$\mathrm{Wn}=3.225 \times 0,77=2483,25$ detik

\section{Menghitung waktu baku berdasarkan metode Westinghouse}

Menghitung waktu baku

perancangan hydraulic power equipment berdasarkan Metode Westinghouse sebagai berikut:

$$
\mathrm{Wb}=\mathrm{Wn}(1+\mathrm{l})
$$

Keterangan:

Wb: Waktu Baku.

Wn: Waktu Normal.

$l$ : Kelonggaran

Menghitung Kelonggaran:

1. Tenaga yang dikeluarkan $: 6$

2. Sikap Kerja $\quad: 1$

3. Gerakan Kerja : 0

4. Kelelahan Mata $\quad: 6$

5. Keadaan Temperatur Kerja : :0

6. Keadaan Atmos $: 10$

7. Keadaan lingkungan yang baik $\frac{: 2}{: 25}+$

Jadi Kelonggaran yang didapat pekerja untuk menyelesaikan pekerjaannya adalah 25\%. Jika dari sampling pekerjaan didapat bahwa kelonggaran untuk terhindarkan adalah 5\%, maka kelonggaran yang harus diberikan untuk pekerja proses kalibrasi alat ukur pressure gauge adalah:

$$
(25+5) \%=30 \%
$$

Jika waktu normalnya 2483.25

detik, maka waktu bakunya adalah

$$
\begin{aligned}
\mathrm{Wb} & =\mathrm{Wn}(1+1) \\
& =2483,25+0.3(2483,25) \\
& =3228.44 \text { Detik }
\end{aligned}
$$


12. Perbandingan waktu sebelum dan sesudah perancangan

Perbandingan waktu proses kalibrasi alat ukur sebelum perancangan dan sesudah perancangan dijabarkan melalui Tabel 2.

Tabel 2. Perbandingan waktu kalibrasi sebelum perancangan dan sesudah perancangan

\begin{tabular}{ccccc}
\hline No & $\begin{array}{c}\text { Ketera- } \\
\text { ngan }\end{array}$ & $\begin{array}{c}\text { Waktu } \\
\text { kalibrasi } \\
\text { sebelum } \\
\text { perancangan }\end{array}$ & $\begin{array}{c}\text { Waktu } \\
\text { proses } \\
\text { sesudah } \\
\text { perancangan }\end{array}$ & $\begin{array}{c}\text { Seli- } \\
\text { sih }\end{array}$ \\
\hline 1 & $\begin{array}{c}\text { Waktu } \\
\text { siklus }\end{array}$ & 3240 & 268.75 & 971.25 \\
\hline 2 & $\begin{array}{c}\text { Waktu } \\
\text { Normal }\end{array}$ & 2498.8 & 206.94 & 291.86 \\
\hline 3 & $\begin{array}{c}\text { Waktu } \\
\text { Baku }\end{array}$ & 3248.44 & 269.04 & 979.40 \\
\hline
\end{tabular}

Keterangan: Sebelum $(1 \mathrm{X}$ Proses Kalibrasi $=1$ Pressure Gauge) Sesudah (1 X Proses Kalibrasi = 12 Pressure Gauge)

Berdasarkan Tabel 2 perhitungan waktu efisiensi proses kalibrasi alat ukur pressure gauge sebelum perancangan dan sesudah perancangan adalah:

$$
\begin{aligned}
& \text { 1. } \frac{2971,25}{3240} \times 100 \%=91,7 \% \\
& \text { 2. } \frac{2291,86}{2498,8} \times 100 \%=91,72 \%
\end{aligned}
$$

$$
\text { 3. } \frac{2979,40}{3248,44} \times 100 \%=91,72 \%
$$

Jadi efisiensi waktu baku dari proses perancangan kalibrasi pressure gauge dengan mengunakan hydraulic power equipment yang dikombinasikan atau sesudah perancangan adalah sebesar $91.72 \%$.

\section{Kesimpulan}

Berdasarkan pengolahan data dan pembahasan yang dilakukan pada penelitian maka dapat diambil kesimpulan bahwa waktu baku proses kalibrasi pressure gauge sebelum dilakukan perbaikan di PT. Surya Toto Indonesia Tbk adalah 3248.44 detik. Setelah mengaplikasikan metode analisis perancangan kerja pada proses kalibrasi pressure gauge di PT. Surya Toto Indonesia Tbk, diperoleh waktu baku proses kalibrasi pressure gauge setelah dilakukan perbaikan adalah 2979.4 detik. Jadi terdapat efisiensi waktu sebesar $91,72 \%$.

\section{Ucapan terimakasih}

Penelitian ini bisa diselesaikan berkat bantuan rekan-rekan dosen Teknik Industri Universitas Pamulang dan para pekerja pada perusahaan PT. Surya Toto Indosesia Tbk di Tangerang untuk itu peneliti mengucapkan terimakasih atas kerjasamanya dan dukungannya.

\section{Referensi}

[1] T. Sefriana, W. Wiyono, and H. Lalu, "Perancangan Proses Order Kalibrasi Alat Ukur Dengan Mempertimbangkan Risiko Untuk Memenuhi Iso 9001:2015 Klausul 7.1.5 Menggunakan Metode Business Process Improvement Di Cv. Xyz," J. Ind. Serv., vol. 3, no. 2, pp. 92-97, 2018.

[2] S. Hariyadi, F. Hidayanti, and S. Gunadi, "Rancang Bangun Sistem Kalibrasi Alat Ukur Tekanan Rendah," J. Ilm. Giga, vol. 18, no. 2, p. 35, 2019, doi: 10.47313/jig.v18i2.573.

[3] F. Teknik, "Antropometri, , Ergonomis ," vol. 12, no. 1, pp. 4856, 2016.

[4] M. Rahayu, "Pengukuran Waktu Baku Perakitan Pena Dengan Menggunakan Waktu Jam Henti Saat Praktikum Analisa Perancangan Kerja," vol. 7, no. 2, 2020.

[5] P. M. Astra, "Politeknik manufaktur astra," vol. 11, no. 8, 2020.

[6] M. Khaery, A. H. Pratama, P. Wipradnyana, and A. A. N. Gunawan, "Design of Air Pressure Measuring Devices Using a Barometric Pressure 280 (BMP280) Sensor Based on Arduino Uno," Bul. 
Fis., vol. 21, no. 1, p. 14, 2020, doi: 10.24843/bf.2020.v21.i01.p03.

[7] Hadi, Anwar. Pemahaman dan Penerapan ISO/IEC 17025:2005:

Persyaratan Umum Kompetensi

Laboratarium Pengujian dan

Laboratarium Kalibrasi. Jakarta :

Gramedia Pustaka Utama, 2007.

[8] Sutalaksana, Iftikar Z. Dkk. Perancangan Sistem Kerja . Bandung : press ITB, 2006.

[9] Lowrey, S.M., Maynard. H.B., Stegemenrten, G.J. Time and Montion Study. New York and London: Mc Graw Holl Book Company, 1940.

[10] Wignjosoebroto, Sritomo. Ergonomi Study Gerak dan Waktu. Jakarta : Guna Widya, 1995.

[11] Budiyanto, E., Yuono, L. D., \& Farindra, A. (2019). Upaya Peningkatan Kualitas dan Kapasitas Produksi Mesin Pengupas Kulit Kopi Kering. Turbo: Jurnal Program Studi Teknik Mesin, 8(1). 